VOLUME 18 NOMOR 2, APRIL 2019

\title{
PERANAN RADAR (REMAJA AKTIF DUTA ANTI ROKOK) DI SMP NEGERI 10 DENPASAR
}

Elisya Julianty Lintin ${ }^{1}$, Ni Made Rai Riastini ${ }^{2}$, I Gusti Ayu Evita Trisnarini ${ }^{3}$, Putu Intan Tillama ${ }^{4}$, I Gede Sutha Arta Pramana $^{5}$

\begin{abstract}
The amount of teenage smokers has significantly increased in the present. The desire to smoke in teenagers is associated with the exposure of peer group. This is triggered by the urge to be accepted in the community and the lack of information. The beginning age of a person to smoke is getting younger. This phenomenon triggers the addiction and increase the vulnerability of serious diseases in the future. Therefore, there should be an effort to empower the teenagers by molding peer educator as RADAR. It has roles to influence their peer friends to avoid tobacco and campaign about the danger of tobacco and recent issues about tobacco in their school. The aims were decreasing the early teenage smokers and creating a sustainable extracurricular that generates regeneration of peer educator in SMPN 10 Denpasar. The methods were 1) Roadshow; 2) Trainings; 3) Selection and final; and 4) Campaign activity. The result showed that there was an increasing score from pretest to posttest after implementing the program which was $25.8 \%$. The activities of RADAR in social media were shown from the amount of likes on each topic which comprised of 200 likes of the danger of tobacco, 90 likes of TAPS, 120 likes of PHW, and 100 likes of KTR. This program succeeded in educating the danger of tobacco in early teenagers and create an extracurricular in school. This program is expected to be applied in another junior high school in Bali.
\end{abstract}

Keywords : Teenager, Smoker, Peer Educator, Cigarette

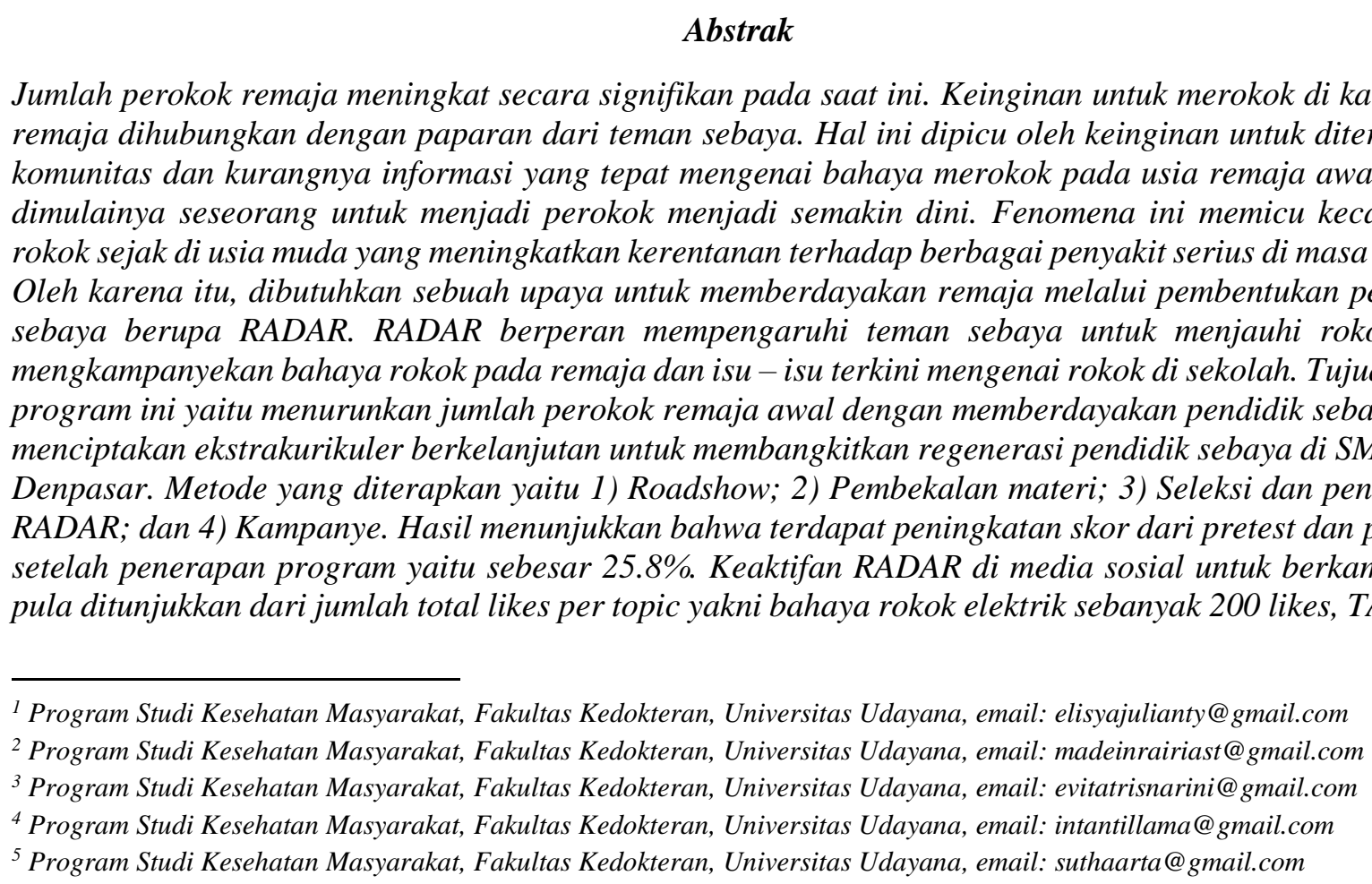


likes, PHW 120 likes, dan KTR 100 likes. Program ini berhasil dalam mengedukasi bahaya rokok pada remaja awal dan membentuk ekstrakurikuler di SMPN 10 Denpasar. Program diharapkan dapat diaplikasikan di sekolah menengah pertama lainnya di Provinsi Bali.

Kata Kunci : Remaja, Perokok, Pendidik Sebaya, Rokok

\section{PENDAHULUAN}

Perilaku merokok di Indonesia pada perokok berumur 10 tahun ke atas cenderung mengalami peningkatan sejak tahun 2007 hingga 2013, yaitu dari 23,7\% menjadi 24,3\% (Widya et al, 2015). Berdasarkan survei yang dilakukan oleh Global Youth Tobacco Survey (GYTS) menyatakan Indonesia sebagai negara dengan jumlah perokok remaja tertinggi di dunia. Tren usia pertama kali mencoba untuk merokok yaitu pada remaja laki-laki usia 12-13 tahun dengan presentase 54,1\% sedangkan pada perempuan usia 14-15 tahun dengan presentase 9,1\%. Berdasarkan Riset Kesehatan Dasar (2013), menunjukkan bahwa persentase perokok usia muda di kabupaten/kota di Provinsi Bali yaitu pada rentang usia 10-14 tahun sebesar 4,6\%, dan usia 15-19 tahun sebesar $36,1 \%$. Jumlah perokok yang ditemukan di Bali yang tertinggi yaitu di Kota Denpasar pada usia 10-14 tahun 4,7\% dan usia 15-19 tahun sebanyak 47,3\% (Riskesdas (2007) dalam Wiratini, NPS, dkk (2015)).

Salah satu faktor penyebab yang dapat memengaruhi perilaku merokok pada remaja adalah pengaruh teman sebaya. Berdasarkan sebuah penelitian disebutkan bahwa sebanyak $75 \%$ remaja pertama kali menghisap rokok ketika sedang bersama teman-temannya, dalam hal ini perilaku merokok terjadi agar dapat menyesuaikan diri dan diterima di dalam suatu kelompok (Simartama, 2012). Alasan bahwa teman sebaya berdampak pada pengaruh kuat bagi para remaja untuk merokok, yaitu pertama, remaja cenderung menghabiskan banyak waktunya untuk berinteraksi dengan teman sebaya dan cenderung terlepas dari pengawasan orang tua. Kedua, rokok telah digunakan sebagai simbol pengenal yang merepresentasikan kelompok sebaya tertentu. Ketiga, paparan berulang dari nikotin dapat membawa remaja untuk berkembang menjadi penyuka aroma tembakau, atau menjadi candu terhadap nikotin melalui reaksi kimia yang meningkatkan gairah untuk merokok (Yarnell, 2012).

Meskipun fakta mengatakan hal demikian, sampai saat ini masih belum ada program pemerintah ataupun sekolah dalam pembentukan agen perubahan (agent of change) di kalangan remaja awal untuk memanfaatkan kesempatan memengaruhi teman sebaya dalam mengurangi tingkat perokok dini di kalangan remaja Sekolah Menengah Pertama. Oleh karena itu, diperlukan pergerakan insan muda untuk membangun inovasi dengan adanya pemilihan remaja Duta Anti Rokok di tingkat Sekolah Menengah Pertama di masing-masing kelas dan dari duta-duta yang terpilih akan bertugas untuk menginspirasi dan mengajak teman-teman sebayanya untuk menjauhi rokok demi masa depan. SMP Negeri 10 Denpasar merupakan salah satu sekolah menengah pertama unggulan di Kota Denpasar yang tidak memiliki organisasi yang bergerak di bidang anti rokok. Sehingga, SMP Negeri 10 Denpasar menjadi sekolah pilihan penulis untuk memulai pilot project RADAR. 
Tujuan program RADAR adalah untuk meningkatkan pengetahuan dan wawasan siswa-siswi SMP Negeri 10 Denpasar tentang bahaya merokok pada usia dini yaitu masa remaja awal serta membangun dan memperkuat peran teman sebaya (peer group) melalui pemilihan duta anti rokok sebagai agen perubahan (agent of change) untuk menginspirasi dan mengajak teman seusianya. Program ini diharapkan dapat berlanjut dengan terbentuknya ekstrakulikuler yang sebagai wadah edukasi mengenai bahaya rokok di SMP Negeri 10 Denpasar, sehingga dapat dilaksanakannya pemilihan RADAR setiap tahunnya di SMP Negeri 10 Denpasar. Program RADAR yang berperan sebagai media pencerdasan yang berguna untuk meningkatkan pengetahuan mengenai bahaya rokok dan isu-isu rokok dengan memberdayakan potensi siswa SMP Negeri 10 Denpasar bermanfaat sebagai media penyebaran informasi melalui media sosial terkait bahaya rokok dan isu-isu rokok khususnya di masyarakat luas. Dalam jangka panjang SMP Negeri 10 Denpasar dapat dijadikan sebagai contoh implementasi program "RADAR (Remaja Aktif Duta Anti Rokok) sebagai Teladan (Role Model) Edukasi Bahaya Rokok Melalui Peran Teman Sebaya (Peer Group) di SMP Negeri 10 Denpasar" ini agar nantinya dapat diterapkan di sekolah lainnya di Denpasar khususnya dan di Bali pada umumnya.

\section{METODE}

Pelaksanaan program RADAR memiliki tahapan sebagai berikut:

\section{a. Roadshow RADAR}

Kegiatan Roadshow RADAR 2018 dilakukan pada tanggal 2 Mei 2018. Kegiatan ini melibatkan seluruh siswa kelas 7 dan 8, serta guru SMPN 10 Denpasar. Bentuk kegiatan berupa sosialisasi kepada seluruh siswa kelas 7 dan 8 SMPN 10 Denpasar mengenai RADAR 2018. Siswa dikumpulkan di halaman sekolah dan diberikan pemaparan mengenai tujuan pelaksanaan RADAR 2018, serta penjelasan mengenai alur pendaftaran RADAR 2018. Selain sosisalisasi langsung pengenalan program RADAR juga dilakukan melalui sosialisasi lansung menggunakan media pamphlet serta media sosial.

\section{b. Pembekalan RADAR}

Pembekalan materi dilakukan kepada seluruh peserta yang sudah melakukan pendaftaran dari perwakilan tiap kelas 7 dan 8 RADAR. Kegiatan dilaksanakan pada tanggal 22 Mei 2018 bertempat di SMPN 10 Denpasar. Sebelum penyampaian materi, dilaksanakan pretest kepada seluruh siswa/siswi kelas 7 dan 8 . Materi disampaikan oleh tim pelaksana dan didampingi oleh dosen pembimbing. Materi yang disampaikan antara lain: bahaya rokok pada remaja, TAPS (Tobacco Advertising, Promotion, and Sponsorship), PHW (Pictorial Health Warning), bahaya rokok elektronik, dan KTR (Kawasan Tanpa Rokok). Kegiatan ini juga diselingi dengan pemutaran video edukasi, permainan interaktif tentang bahaya rokok, serta yang terakhir yaitu peragaan tentang bahaya rokok memasuki organ paru dengan menggunakan alat peraga.

\section{c. Seleksi dan Penobatan}


Setelah melalui tahap pembekalan seluruh peserta RADAR diseleksi untuk menyaring peserta yang nantinya akan dinobatkan sebagai RADAR. Seleksi dilakukan melalui dua tahap yaitu seleksi wawancara yang dilaksanakan setelah pembekalan pada tanggal 22 Mei 2018 serta presentasi penugasan esai popular mengenai isu-isu yang berkaitan dengan rokok yang dilaksanakan pada 26 Mei 2018. Pada tahap wawancara, peserta RADAR diwawancarai dan dinilai oleh 3 orang juri dari mahasiswa yaitu tim penulis. Para juri akan menanyakan beberapa pertanyaan mengenai komitmen peserta RADAR, pengetahuan secara umum mengenai bahaya rokok serta isu terkait rokok, serta beberapa pertanyaan lain yang sudah ditentukan. Peserta RADAR yang nantinya lolos seleksi wawancara akan diberikan penugasan untuk membuat esai ilmiah popular dengan tema Bahaya Rokok Terhadap Remaja, Iklan, Promosi dan Sponsor Rokok atau Tobacco, Advertising, Promotion and Sponsorship (TAPS), Pictorial Health Warning (PHW), serta Rokok Elektronik. Penugasan esai tersebut dipresentasikan secara lisan dan diberikan alokasi waktu selama 7 menit termasuk sesi tanya jawab.

Penentuan juara I, juara II, dan juara III RADAR diberikan kepada 6 orang peserta (3 pasang putra-putri) dengan jumlah skor tertinggi. Selain itu, terdapat penobatan untuk pemenang RADAR favorit yang ditentukan berdasarkan jumlah like pada foto peserta yang terdapat di akun instagram @ radarunud. Juara I, II, dan III mendapat penghargaan berupa Piala, Selempang, Piagam, dan Sejumlah uang. Juara Favorit akan mendapat penghargaan berupa Selempang dan Piagam. Selebihnya 12 RADAR lainnya mendapatkan selempang

Para siswa/siswi yang terpilih sebagai 20 besar RADAR akan mendapatkan lisensi sebagai Duta Anti Rokok di SMP Negeri 10 Denpasar selama 1 periode kepengurusan dan tergabung dalam paguyuban RADAR.

\section{d. Kampanye}

RADAR sebagai peer educator memiliki tugas untuk mengampanyekan bahaya rokok serta isu-isu terkait mengenai rokok. Kegiatan kampanye berlangsung dari tanggal 25 Juni 9 Juli 2018. Kampanye dilakukan melalui media sosial, siaran radio, hingga sosialiasasi langsung ke seluruh kelas di SMPN 10 Denpasar, serta tempat umum. Setelah kegiatan kampanye dilakukan oleh RADAR, siswa/siswi kelas 7 dan 8 SMPN 10 Denpasar diberikan posttest dengan tujuan untuk dapat melihat peningkatan pengetahuan siswa/siswi mengenai bahaya merokok dan isu-isu terkait rokok.

\section{e. Keberlanjutan program}

Keberlanjutan dari program RADAR adalah terbentuknya ekstrakulikuler yang akan menghasilkan regenerasi RADAR setiap tahunnya. Pelaksanaan RADAR sebagai ekstrakurikuler akan berpedoman pada modul dan video dokumentasi RADAR yang dibuat oleh tim penulis.

\section{HASIL DAN PEMBAHASAN}

Seluruh rangkaian kegiatan program RADAR telah terlaksana. Identifikasi ketercapaian program RADAR program dapat ditinjau dari: 


\section{a. Keaktifan RADAR}

Peran aktif dari RADAR sangat dibutuhkan dalam pencapaian program RADAR. Setelah penobatan, RADAR telah melakukan berbagai kegiatan kampanye antara lain: (1) menyebarkan informasi seputar bahaya rokok dan isu-isu terkait rokok melalui media sosial; (2) melakukan siaran radio di Phoenix Radio 91.00 FM Bali; (3) sosialisasi secara langsung kepada seluruh siswa-siswi kelas 7 dan 8 SMPN 10 Denpasar. Kampanye RADAR melalui media sosial ditinjau berdasarkan jumlah total like dari seluruh RADAR untuk setiap topik yang disebarkan melalui akun instagram masing-masing RADAR. Berikut hasil jumlah like dari kampanye melalui instragram:

Tabel 1. Jumlah Total Like Setiap Topik yang Disebarkan Melalui Instragram

\begin{tabular}{|l|l|c|}
\hline No. & \multicolumn{1}{|c|}{ Topik } & Total Like \\
\hline 1. & Bahaya Rokok Eletrik & 200 \\
\hline 2. & TAPS (Tobacco Advertising, Promotion, and Sponsorship) & 90 \\
\hline 3. & PHW (Pictorial Health Warning) & 120 \\
\hline 4. & KTR (Kawasan Tanpa Rokok) & 100 \\
\hline
\end{tabular}

\section{b. Peningkatan pengetahuan siswa-siswi SMPN 10 Denpasar mengenai bahaya merokok dan isu-isu terkait rokok}

Peningkatan pengetahuan siswa-siswi kelas 7 dan 8 SMPN 10 Denpasar dilihat dari hasil pretest dan posttest yang telah dilakukan. Pelaksanaan pretest dilakukan sebelum pembekalan materi kepada RADAR, sedangkan posttest dilakukan setelah kegiatan kampanye oleh RADAR.

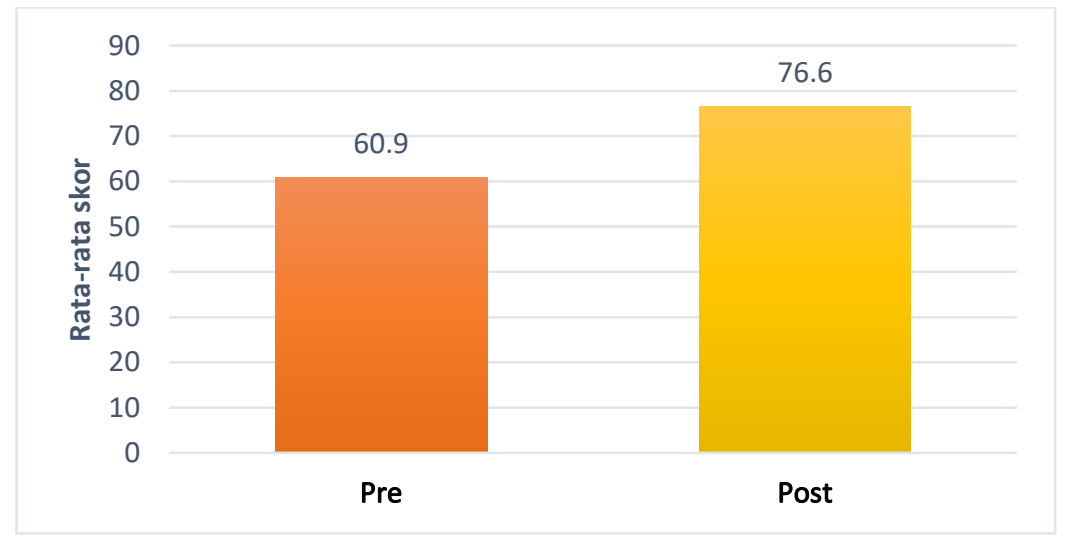

Gambar 1. Grafik Rata-Rata Skor Pengetahuan Siswa-Siswi Kelas 7 dan 8 SMPN 10 Denpasar Sebelum dan Sesudah Kampanye RADAR.

Berdasarkan grafik pada gambar 1, dapat disimpulkan bahwa terdapat peningkatan pengetahuan siswa-siswi kelas 7 dan 8 SMPN 10 Denpasar sebesar 15,7 atau 25,8\% setelah adanya peran RADAR dalam mengampanyekan mengenai bahaya rokok dan isu-isu terkait rokok. 


\section{c. Keberlanjutan program RADAR}

Program RADAR telah mendapat persetujuan dari kepala SMPN 10 Denpasar untuk menjadi sebuah ekstrakulikuler resmi yang akan menghasilkan regenerasi RADAR setiap tahunnya. Modul dan video dokumentasi mengenai pelaksanaan RADAR diserahkan kepada pihak SMPN 10 Denpasar untuk menjadi pedoman dalam melaksanakan ekstrakurikuler tersebut.

\section{KESIMPULAN}

Memperhatikan pelaksanaan dan hasil program RADAR ini, dapat disimpulkan sebagai berikut; 1) Metode yang digunakan yaitu pencegahan munculnya perokok baru di usia remaja awal melalui peran teman sebaya sebagai Remaja Aktif Duta Anti Rokok dengan mengedukasi teman seusianya mengenai bahaya rokok dan isu-isu rokok; 2) Program ini telah menghasilkan 20 RADAR yang akan bertugas mengampanyekan dan mengedukasi teman seusianya serta orang disekitarnya mengenai bahaya rokok dan isu-isu rokok; 3) Program ini telah berhasil meningkatkan pengetahuan siswa-siswi SMP Negeri 10 Denpasar mengenai bahaya rokok dan isuisu rokok sebesar 25,8\% dilihat dari hasil pretest dan posttest yang telah diberikan; 4) Program ini telah berhasil menjadi ekstrakurikuler di SMP Negeri 10 Denpasar sebagai wadah untuk melanjutkan program ini setiap tahunnya.

\section{UCAPAN TERIMAKASIH}

Ucapan terimakasih kami sampaikan kepada berbagai pihak yang telah membantu pelaksanaan Program RADAR ini, yakni Direktorat Jenderal Pembelajaran dan Kemahasiswaan Kementerian Riset, Teknologi, dan Pendidikan Tinggi atas bantuan dana kegiatan; Universitas Udayana; serta I Made Kerta Duana, S.KM, MPH atas bimbingannya sehingga program RADAR ini dapat terlaksana dengan baik.

\section{REFERENSI}

GYTS. 2014. Global Youth Tobacco Survey: Indonesian Report 2014. WHO

Kementrian Kesehatan RI. 2013, Badan Penelitian dan pengembangan kesehatan, Riskesdas 2013

Simartama, S. 2012. Perilaku Merokok Pada Siswa Siswi Madrasah Tsanawiyah Negeri Model Kuok Kecamatan Bangkinang Barat Kabupaten Kampar Provinsi Riau Tahun 2012.

Widya, DN, Nurgahayu, Idris, FP. 2015. Faktor Yang Berhubungan Dengan Kepatuhan Perokok Terhadap Kebijakan Kawasan Tanpa Rokok (KTR) di Bandara Internasional Sultan Hasanuddin Tahun 2015.

Wiratini, N.P.S. Yanti, N.L.P.E, Wijaya, A.A.N.T. 2015. Pengaruh Peer Education Terhadap Perilaku Merokok Pada Remaja di SMAN “ X” Denpasar. 
Yarnell. Lisa, M. dkk. 2012. Classroom Norms and Individual Smoking Behaviour in Middle School. 